\title{
The Puzzling Life of Autistic Toddlers: Design Guidelines from the LINKX Project
}

\author{
Helma van Rijn and Pieter Jan Stappers \\ ID-StudioLab, Faculty of Industrial Design Engineering, Delft University of Technology, Landbergstraat 15, \\ 2628CE Delft, The Netherlands
}

Correspondence should be addressed to Helma van Rijn, h.vanrijn@tudelft.nl

Received 30 September 2007; Revised 17 April 2008; Accepted 24 July 2008

Recommended by Adrian Cheok

This paper presents guidelines for designers to help them consider what children with autism value in interactions with their environment. The guidelines were developed during the LINKX project in order to design a language learning toy for these children and are based on literature study, expert interviews, generative techniques, and prototype testing with users. We present both the theoretical or practical background of each guideline together with a discussion how the guideline was evident in the prototype of LINKX. Testing the prototype in the real world helped us to shape the prototype and the guidelines. This paper aims to share our guidelines with the design research community, so that others can use them as steppingstones in their work.

Copyright (C) 2008 H. van Rijn and P. J. Stappers. This is an open access article distributed under the Creative Commons Attribution License, which permits unrestricted use, distribution, and reproduction in any medium, provided the original work is properly cited.

\section{Introduction}

Interactive toys are opening up new learning and play opportunities for children with autism. For example, the toys can keep track of the child's progress, evolve with a child, or give controlled feedback. But for this to succeed, the design of these toys must fit well within the experiential world of these children. Children with autism live in an experiential world that is different from that of other children or adults. Therefore, designers need to make effort in to understand these children's needs and preferences.

Although an admirable body of theory on autism is available in popular science (see, e.g., $[1,2]$ ), much of it is not helpful for designers. Moreover, absorbing literature is often too time-consuming for design teams. We see two important ingredients that do work for designers: contact with the children to achieve empathic understanding, and guidelines on an operational level to help them translate that understanding into product ideas and concepts.

In the LINKX project, we developed guidelines ourselves in order to design a language-learning toy for children with autism. These guidelines, implemented in the design, were acquired through study and contextual research, such as expert interviews, generative techniques, and prototype testing with users. The prototype and the research techniques have been described [3-5]. In this paper, we want to share our guidelines with the design research community, so that others can use them as stepping-stones in their work.

\section{Background of Autism}

Autism is an inborn developmental disorder that affects around 91 people in every 10000 . Much variation exists between autistic children, and even with one child the diagnosis can change over time. Affected children may display a range of disabilities at many levels, such as impairment in social relationships, communication, and imagination [6]. Therefore, it is best to use the term "autism spectrum disorder" (ASD), although we use the term "children with autism" in this paper. The disorder distinguishes a number of classes, including pervasive developmental disordernot otherwise specified (PDD-NOS), Aspergers Syndrome (sometimes referred to as "high-functioning autism"), and classic autism.

\subsection{Puzzling Your Perceptions Together}

The neurological setup of the autistic brain makes children with autism process information differently from children 


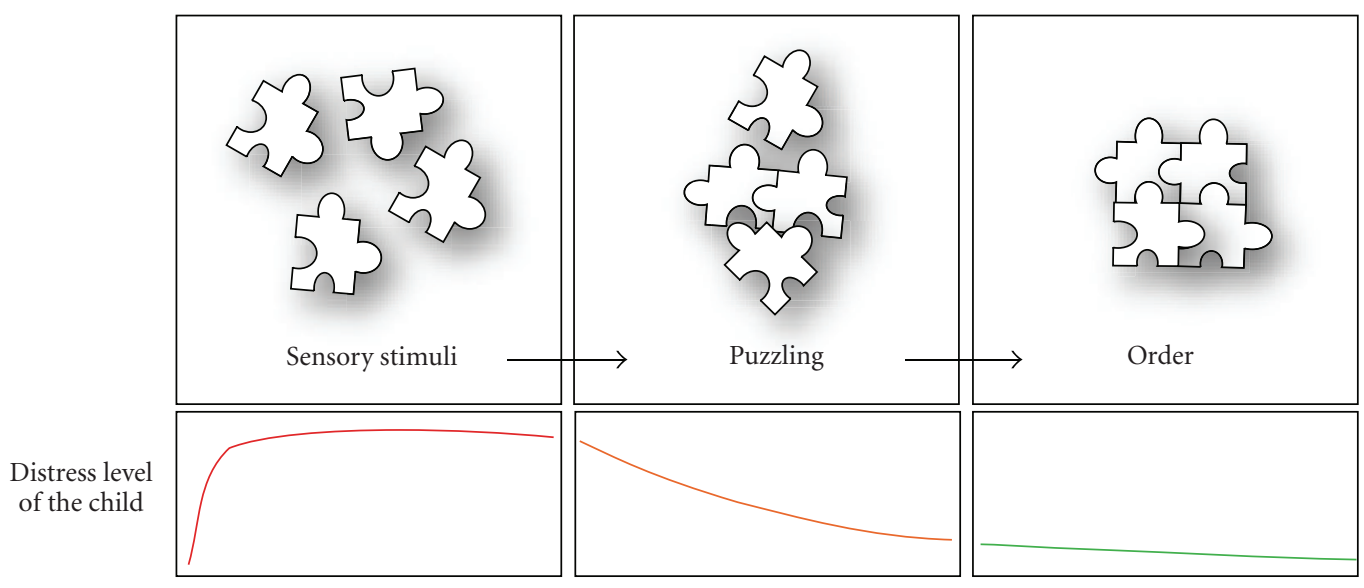

Figure 1: Children with autism need to puzzle their perceptions together to create order. Before puzzling, the child feels distress. After puzzling, the order makes the child feel at ease.

with typical development. Thus, children with autism experience sensations differently and also have difficulties with understanding these sensations.

Unlike most people, children with autism perceive sensations, such as sound, smell, and pain, as incoherent fragments. They do not automatically integrate different sensations into a meaningful whole as most people do. Therefore, they can be very sensitive to certain sensations, and insensitive to others. For example, a child can feel distress because of sticky materials, while it does not notice pain at all.

These children also struggle with sensemaking. Temple Grandin, an adult with autism who could not speak as a child, describes in her book her difficulty to come up with new categories [7]. When she was little, she used to categorize cats and dogs by their size. After her neighbours got a small dog, she had to come up with a new feature to make the distinction, which became the nose. Children with autism need to consciously make categories for everything they hear, see, smell, or feel. Each time something needs to be processed, the child has, in the words of de Bruin [8], to "puzzle it together." The time needed for this puzzle can vary from seconds to months. For example, one mother tried to teach her child to say the word "cookie." After trying it for weeks, she finally gave up. Surprisingly, the child said the word himself a month later. Apparently, it took the child that long to incorporate the word. This process of puzzling your perceptions together is visualized in Figure 1. For children with autism, it is important to eventually complete these puzzles in order to get some peace of mind.

This overall explanation about how children with autism process information is important for understanding the behaviour, needs, and feelings of these children. Most research on autism has brought forward classifications [9, 10], biological facts, or theories [11, 12]. Although this is valuable, it does not sufficiently inform and inspire designers. Designers mainly need to know and understand the behaviour and feelings of the children when they interact with "things" around them, such as toys and people. We deliberately categorised people as "things," because that is how many children with autism regard them. They have difficulty in relating to people. Most of us, including designers, have difficulty in imagining what this must be like, because we are used to conceive our environment in largely social terms.

\subsection{The Three Boys Involved in the LINKX Project: Beer, Robbert, and Jakob}

Three parents chose to cooperate in the LINKX project in response to a letter in which we asked for their expertise. The parents and their children (see Figure 2) were involved throughout the whole design process. These boys helped us to gain a general view on autism, because they differed in diagnosis, age, and language level. Although one child was easier to make contact with than the others, all of them could be triggered to try something new. From the children and their caregivers, we learned how creating order is a central activity in their lives. This is their only way to deal with the world, because of their difficulty processing information. The children will serve as examples for many of the guidelines.

\section{A Toy Designed for Autistic Children: Learning Words with LINKX}

Before going into depth about guidelines on how to design for autistic children, we first introduce the concept design LINKX, depicted in Figure 3 [3]. LINKX was designed as an interactive toy to help children learn their first 100 words, such as "door," "table," and "cabinet." The toy consists of speech-o-grams and interactive blocks. Before play starts, a caregiver prepares the toy by speaking words into the speecho-grams. For example, a parent records the word "cabinet" in a speech-o-gram and attaches it to the cabinet. Next, children can start to play by linking blocks to speech-o-grams or to other blocks. Each time a block connects, it changes its lights and speaks the word. For example, when a child links a block with the speech-o-gram described above, the word "cabinet" moves into this block. When ready, this block plays the word 


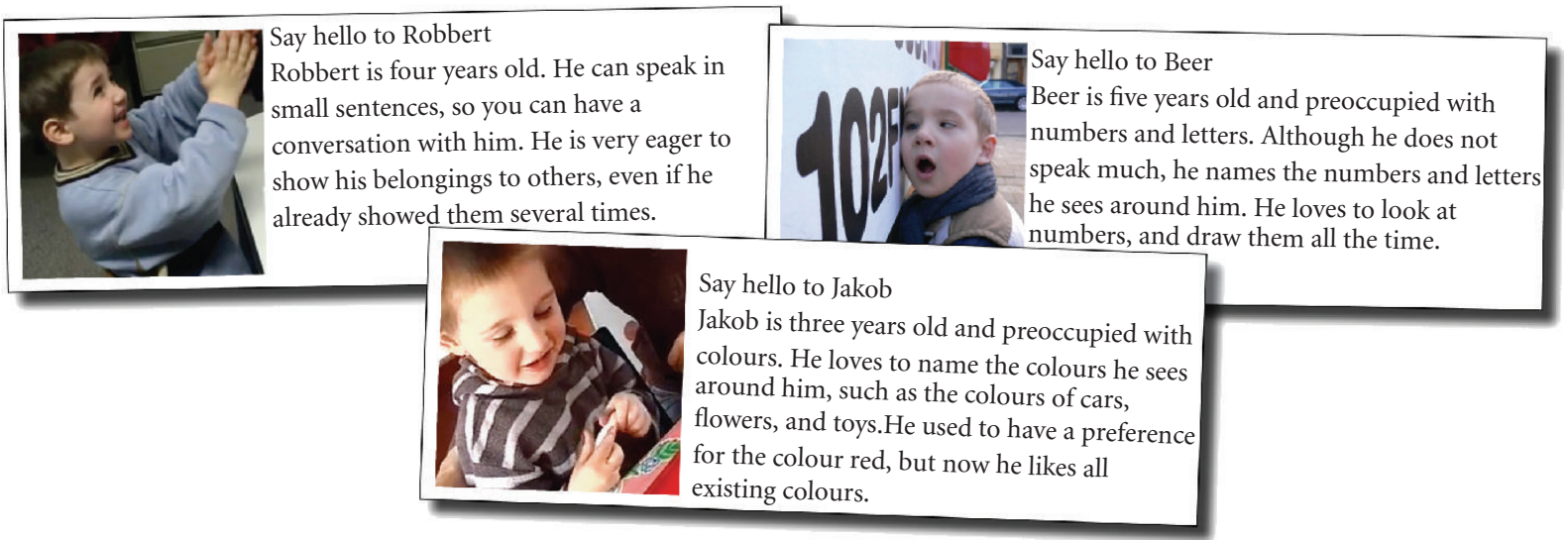

FIgURE 2: A short introduction to the three children in the LINKX project.
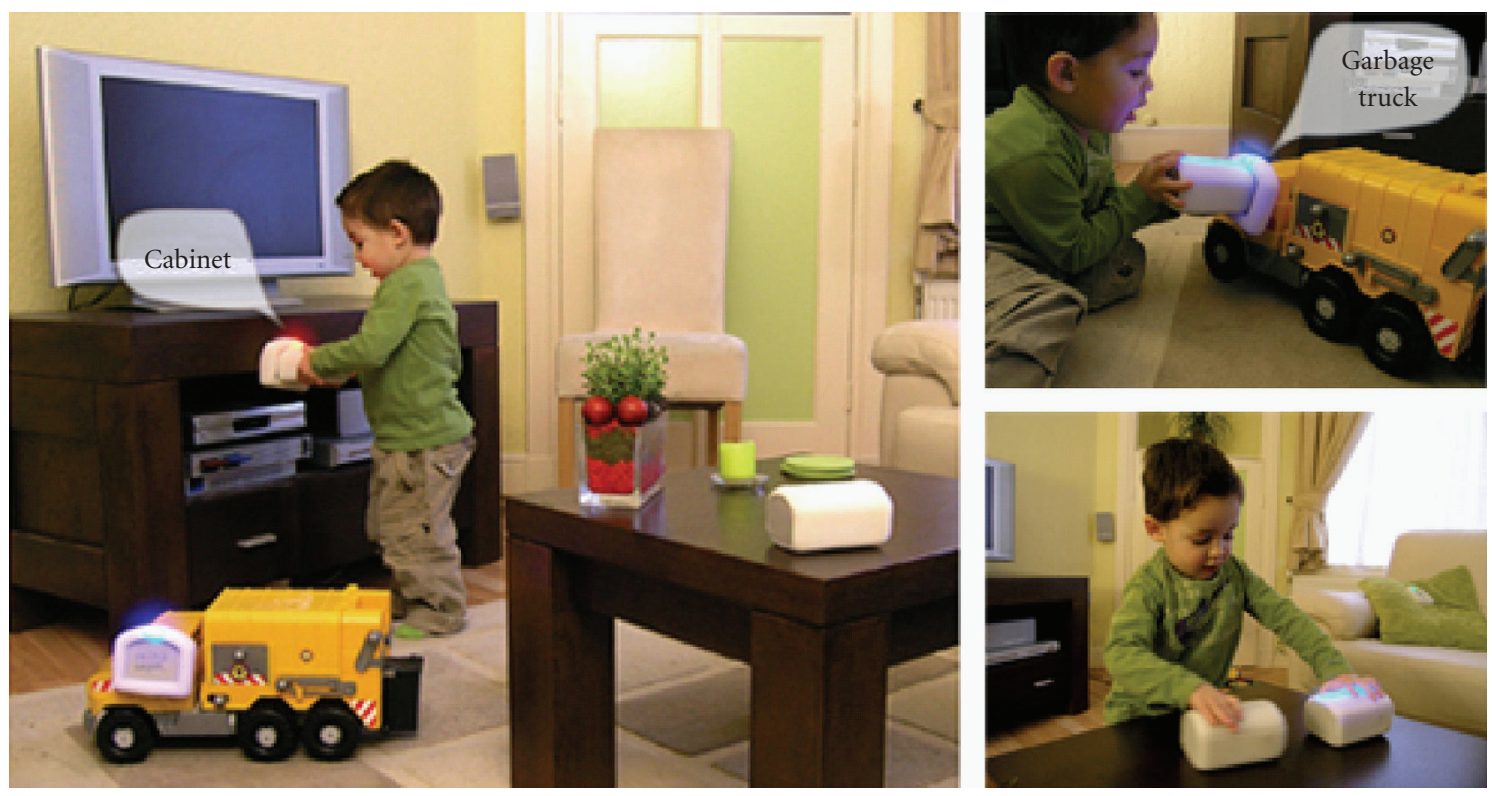

FIGURE 3: A presentation of LINKX, the concept design based on guidelines discussed in this paper. By playing with blocks, children cause the blocks to play the word they received from objects in their everyday environment. For example by connecting a block to the speech-o-gram attached to the cabinet, the block says "cabinet."

"cabinet." Each speech-o-gram has its own colour, which travels with the word, to help children to predict the result of making a new link. In this way, children can explore names of objects in their everyday environment by playful interaction. The LINKX project website contains a movie that shows the concept in use by the three involved children [5].

LINKX employed the guidelines, which are described in detail in the next section as follows. First, the fixed location of the speech-o-grams structured the child's environment. Explicit structure is important for children with autism. The sensorial quality of feedback such as the lights changing their position in the blocks and colour was fascinating for them. This is not only because the children enjoy sensory stimuli such as sound and light so much, but also they enjoy the predictability of when these stimuli appear each time after they made a link. For that reason, they liked to link the play elements together again and again. The blocks confirmed over and over that the child was in control. The children showed they had an excellent memory for sensory detail, because days after playing with the prototype, they still remembered the speech-o-gram's colours. Also during their play, the children remembered what word was inside a block with the help of the colour.

\section{Guidelines on How to Design for Children with Autism}

The attention to designing for children with autism is rather new. Earlier efforts have focused on the disorder itself, with an emphasis on curing a disease rather than improving the way the children can function with such an 


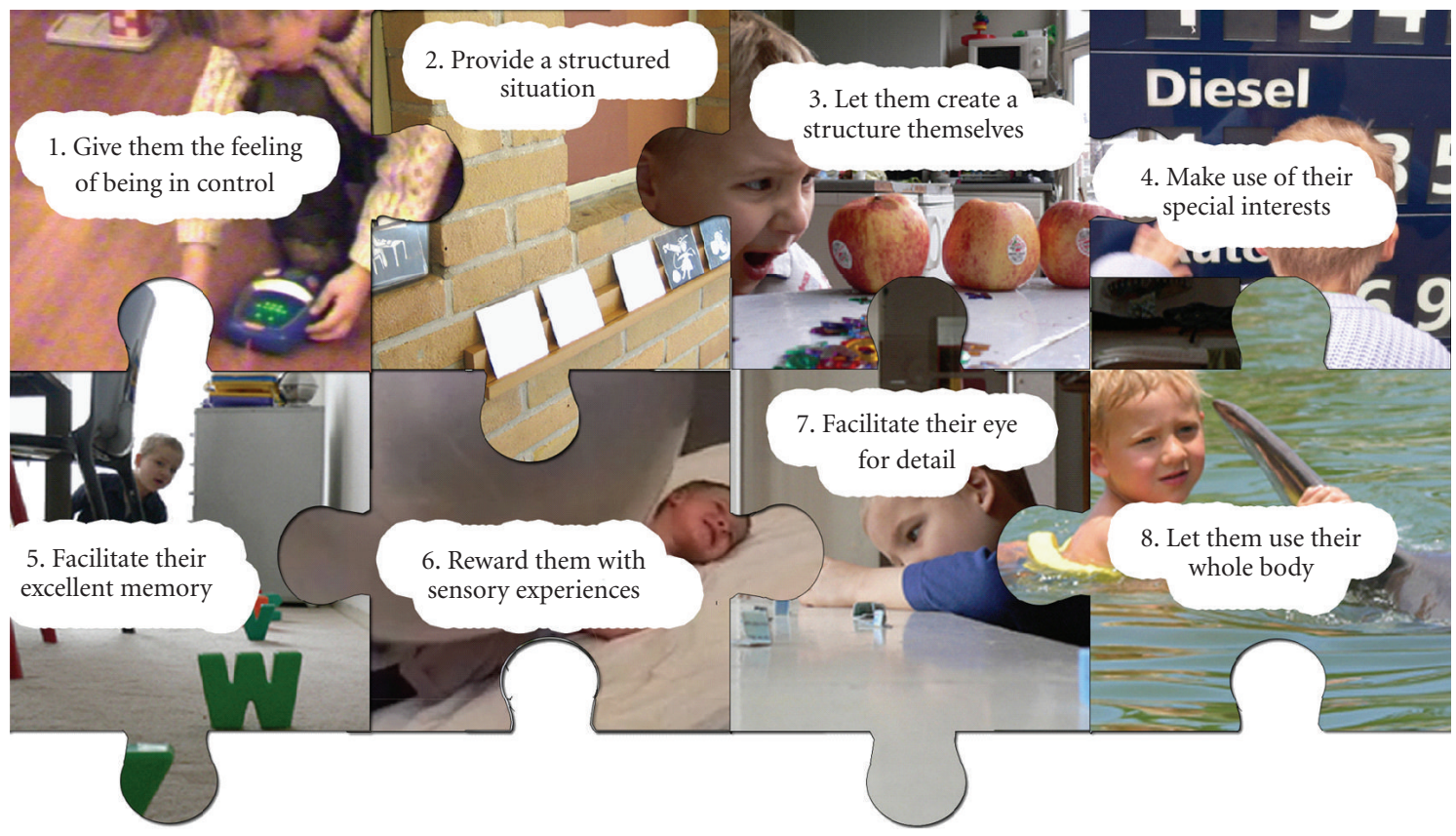

FIGURE 4: An overview of the design guidelines on how to design for children with autism. This puzzle is unfinished on purpose, to indicate that we expect more insights will follow in the coming years, and want to invite others to think along and help to extend it.

impairment. Approximately thirty-five years ago, researchers and designers started to realize the importance of using technology for their treatments (see, e.g., $[13,14]$ ). Moreover, scientists and practitioners realize it cannot be cured at present. This indicates a need for guidelines on operational level to come to products for these children.

Figure 4 depicts an overview of our guidelines as an open-ended jigsaw puzzle, inviting others to think along and help to complete it.

In this section, we will explain each guideline, or puzzle piece, by giving theoretical background and examples from practise combined with how we implemented this in LINKX, the interactive toy we presented earlier. The concept of LINKX was designed on the basis of the guidelines. By means of building the prototype and testing it with the children we could evaluate our guidelines. Therefore, we present the guideline combined with LINKX examples. To illustrate this, the following figures show for each guideline a pair of puzzle pieces, in which the left piece was taken from Figure 4, the right piece from the design of LINKX.

\subsection{Give Them a Feeling of Being in Control}

Children with autism often have no idea how to make sense of their surroundings. Their way of processing information makes them feel they have little or no control over the situation. For that reason, the children enjoy interactions that make them feel in control. In the literature, this preference of children with autism is described in several cases (see, e.g., $[10,15])$. Beer illustrates this preference with his alphabet toy computer. For example, he likes to press the letter "B" and hear it say "bee" over and over. On other days, he

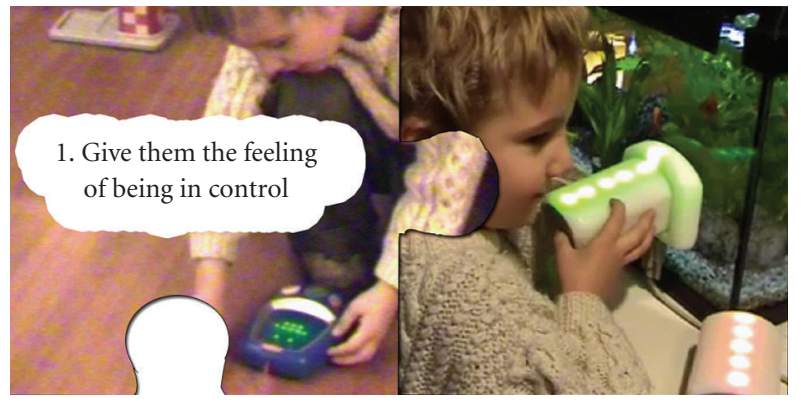

Figure 5: A sense of control. (a) Beer playing with his little number computer: by pushing the button he makes it count from one to ten. (b) Beer playing with LINKX: by linking a block to the speecho-gram he makes it say the word "fishbowl."

prefers the letter " $\mathrm{A}$ " or "C." He adores the lights and sounds that are triggered at his command. The same goes for his little number computer, which is depicted in Figure 5. This example shows how a product makes him feel in control by means of direct feedback, given at the position of the trigger and immediately afterwards. In that way, children can predict the effects of their actions. By triggering action over and over, the children reassure themselves that they are in control of the toy.

In LINKX, the children felt in control when linking blocks. As a result of each link, a word and its associated colour travel from one block to the other. Direct feedback was given by light and sound. The little smile on their faces showed they were happy when the blocks turned on their lights and played a sound at their command. Beer and Robbert even broke out in laughter. The blocks clearly made 


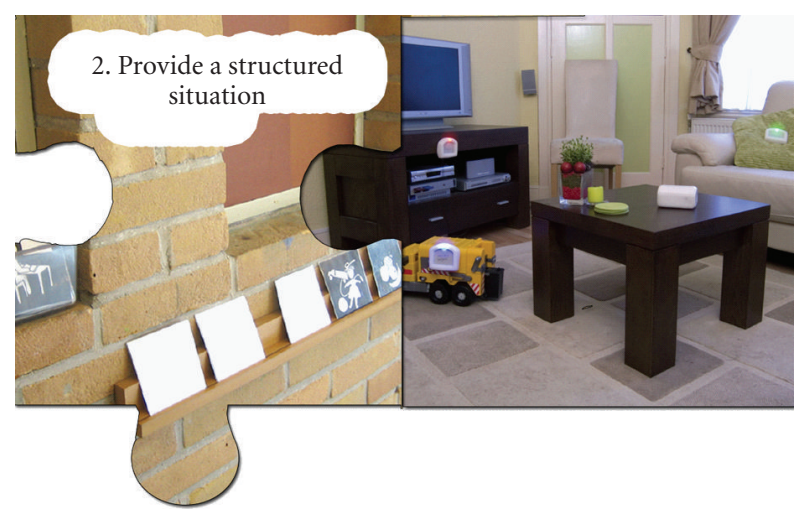

FIGURE 6: Structure: (a) a day-planner at a school for autistic children; activities are planned in time by means of pictograms. When an activity is completed, the pictogram is flipped over in order to provide structure. (b) An illustration of LINKX in a living room; the game is structured by means of speech-o-grams that have a fixed position, word, and colour.

them feel good about themselves. The importance of giving them the feeling of being in control became clear on the occasional moments the prototype gave a delayed or wrong reaction. For example at one time, the colours of two speecho-grams interchanged. A red speech-o-gram attached to the kitchen cabinet became green, while the green one on the bucket became red. Jakob immediately sensed this loss of control and started to cry in distress. He refused to play again with the toy during that session. This example shows the importance of consistent and predictable product behaviour for these children.

\subsection{Provide a Structured Situation}

Children with autism have difficulty changing from one activity into another [16]. Their way of processing information makes it difficult for them to know the order of activities or what will happen in what situation. Activity schedules have proven to be successful (see, e.g., $[17,18]$ ). Visual prompts, such as the day-planner depicted in Figure 6, stay visible at all times. The day-planner provides a structure, because the child is informed about the activities in time. When an activity is completed, the corresponding pictogram is flipped over, indicating it is time for the next activity. This structure helps them to both learn actions such as the sequence for going to the toilet, as well as providing a safe and structured environment in which a child can learn.

In LINKX, a structured situation is provided by means of the speech-o-grams (see Figure 6). These speech-o-grams are labels on which a parent can leave a visual prompt (e.g., pictogram or written word) and an audio prompt (spoken word). Both the presence of speech-o-grams on objects and the predictable result from each link structure the play situation. The fixed location, fixed content, and fixed colour of speech-o-grams give the children peace of mind. However, to challenge children to learn new words, parents can change

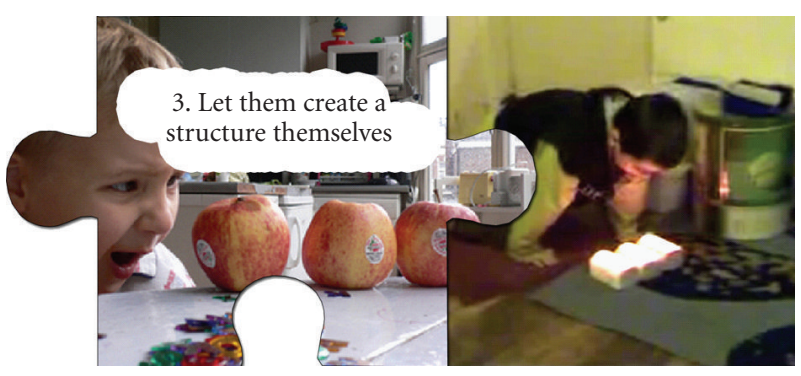

Figure 7: Organising: (a) Beer loves to make sequences of objects; here you see Beer making a sequence with apples. (b) Robbert playing with LINKX; he loves to make blocks into the same colour and arrange them in groups.

the position, content, and colour of one or more speech-o$\operatorname{gram}(\mathrm{s})$, whenever the child is ready for it.

\subsection{Let Them Create a Structure Themselves}

Not only do the children enjoy a structured situation, they enjoy creating a structured situation themselves as well. They like to play with toys they can organize, such as the game "memory" or jigsaw puzzles, and especially love to complete those games. A missing piece can cause panic. The children enjoy looking for similarities and differences as well. The children create structure by making differences explicit. Another thing they like to do is arranging objects in space. For example, Beer loves to arrange objects, such as apples in a sequence (see Figure 7), and looks for differences and similarities in that as well.

In LINKX, we tapped into their preference to create structure, because the blocks and speech-o-grams can be seen as a three-dimensional puzzle. By connecting the blocks to the speech-o-grams, the corresponding word travels from that speech-o-gram into the block. Moreover, the blocks can be organised nicely into a line or a group of blocks varying in colour. Robbert for example liked to make collections of blocks in one colour. Over and over, he made them all green, then blue, and red, and put them nicely together (see Figure 7). Beer on the other hand, preferred to reserve one block for the colour red, and another one for green. His structure lay in appointing one colour to one specific block.

\subsection{Make Use of Their Special Interests}

Some children develop special interests to create structure. Focusing on specific aspects of perception helps the children to make sense of the things they see, feel, and hear. For example, Jakob has special interest in colours, Robbert in sound (music in particular), and Beer in numbers (see Figure 8 ). These elements are everywhere and the children experience them as important regularities in daily life. These special interests can serve as a means to elicit them to interact with something and learn.

As expected, Robbert paid a lot of attention to the sounds (or words) the blocks produced. Although LINKX' colours elicited Jakob to play, it distracted him from learning. He 


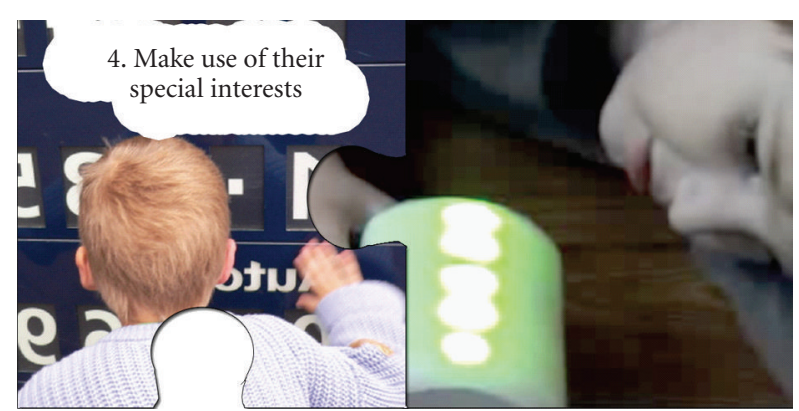

FIGURE 8: Special interests: (a) Beer's special interest is numbers. They are everywhere and provide him a safe feeling. (b) Jakob's special interest in colours encourages him to play with LINKX, although it hinders him from learning words.

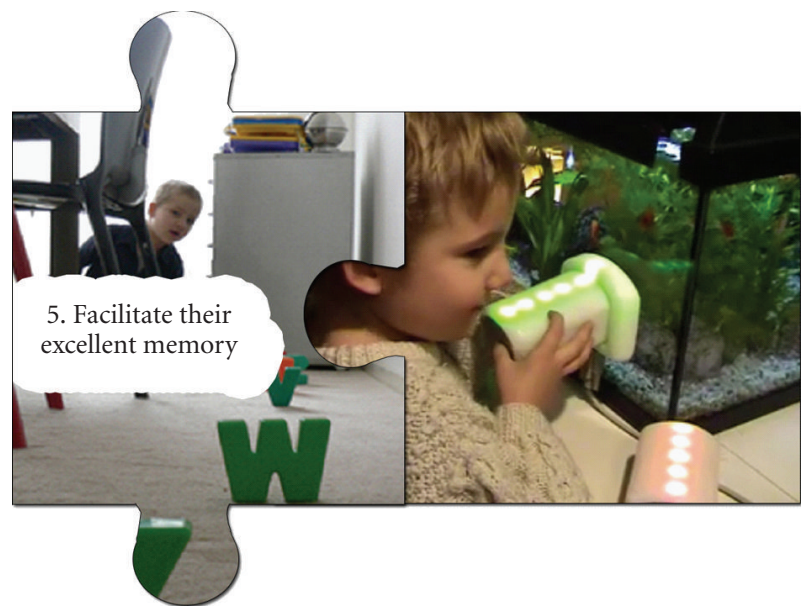

Figure 9: An excellent memory: (a) Beer playing with his alphabet letters on the floor; he knows its sequence by heart, so he can lay the alphabet from "A" to "Z" and from "Z" to "A." (b) Beer plays with LINKX; he remembered the green lights belong to "fishbowl" and the red ones to "window."

was so focused on all the beautiful colours that he could not pay attention to the words LINKX aimed to teach him. His parents suggested it would be best for Jakob to use only one colour for all speech-o-grams, such as white. In that way, he could focus better on the sound. So, special interests can both help and hinder children in their play.

\subsection{Facilitate Their Excellent Memory}

Children with autism have a much better (visual) memory than children with typical development. An example that illustrates their excellent memory is the fact that Beer can arrange the alphabet from "Z" to " $A$ " in a few seconds (see Figure 9). We have to "think backwards" but he just "sees" it. If our designs make use of their memory skills, we may help them understand more and learn better.

We could explore what Robbert remembered, because he speaks in small sentences and gives answers to questions. For the other two children in the LINKX project, this was impossible. After Robbert played with LINKX the second

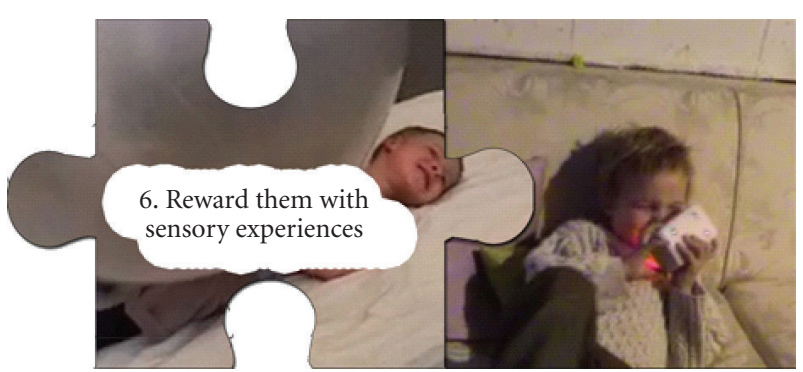

Figure 10: Sensory experiences: (a) Beer gets rewarded with deep pressure during speech therapy. The speech therapist rolls the ball roughly over his body. This makes him feel relaxed and happy. (b) Beer playing with LINKX; he likes to look at the coloured lights from very close and laughs out loud.

time, we removed the speech-o-grams and the blocks and put it away. Next, his father asked him whether he knew the colours of the speech-o-grams, which were attached to different objects, such as a cat litter box, kitchen door, carpet, and bike. Surprisingly, Robbert not only knew the colours of objects he had just played with, but he also knew the colours belonging to objects from the week before. For example, when his father asked, "what colour belongs to the bike?", Robbert answered, "the bike is red!." However, he not only remembered all of the colours, we discovered he could also name the gender of the voice that spoke each word. Both his mother and father had recorded words in LINKX. Although he did not recognize his parents from their voices, he did remember the gender of the person that had spoken the word. When asked, "who is the bike," he answered, "the bike is a mister."

\subsection{Reward Them with Sensory Experiences}

Children with autism often enjoy specific sensations. For example, Robbert is sensitive to sounds. The low pitch of a truck that drives through his street distresses him. However, he loves to put a little vibrating toy, which is meant to be looked at, against his ear to hear a low-pitched sound. Jakob's mother said, "stimuli are less disturbing when they are expected. It helps a lot when the child is in control over the stimuli." Although these children can be highly sensitive, or insensitive, to stimuli, they truly enjoy sensory rewards, such as sounds, music, and vibration, and deep pressure, as described by Grandin [7]. Figure 10 shows how Beer enjoys the deep pressure of a big ball being pushed onto his whole body.

The occasions when the prototype malfunctioned clearly exposed the children's sensory preferences and attention. For Robbert, LINKX' sounds were very important. When he linked a block to a speech-o-gram on the cat's litter box, the block's lights turned red, but the sound was not produced. After a moment, Robbert instructed the block to "say litter box." For Jakob, LINKX' colours were very important. Each time a block changed its colour, Jakob enthusiastically pronounced the colour "red," "green," or "blue." He did not mind the two times that the sound failed. 


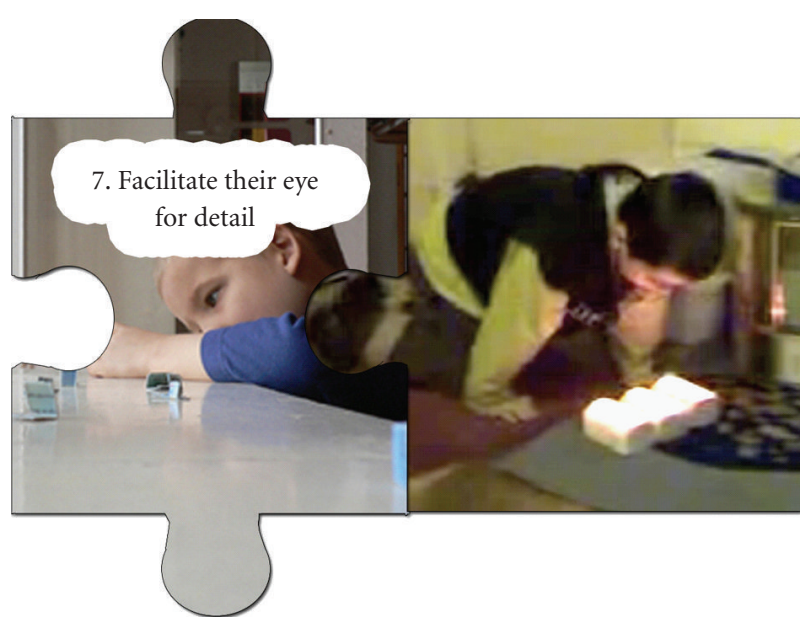

FiguRE 11: Eye for detail: (a) Beer investigates pieces of paper on the table. (b) Robbert counts five red lights on top of the blocks instead of the number of red blocks on the floor.

Although it seems that Jakob did not learn anything from playing with LINKX, since he focused on the colours, we are not sure. For a long time, it seemed Beer focused only on the lights as well, but later on, he surprised us, when we unexpectedly heard him mutter the word "fishbowl" as he walked towards the fishbowl. Maybe this could be the case for Jakob as well. Some children need more time to puzzle than others.

\subsection{Facilitate Their Eye for Detail}

Part of the children's excellent memory is their great eye for detail. When something changes, even a tiny detail, an autistic child will often notice immediately, while our blunt senses overlook it completely. For example, Robbert has a detailed view of books, CDs, and DVDs. When his father adds a new DVD to the row of DVDs, he notices immediately, only by looking at the sides of the covers. Also Beer likes to investigate things in detail (see Figure 11). He notices the smallest details around him.

While playing with the prototype of LINKX, Robbert's eye for detail was again clear when his mom asked him how many "red's" there were. Robbert immediately said, "five." His mom answered, "no, I see one, two, three blocks." Now Robbert counted, "one, two, three, four, five," pointing at the red lights shining on one block instead of counting the three red blocks lying on the floor. Jakob also counted the lights on top of the blocks out loud.

\subsection{Let Them Use Their Whole Body}

Children with autism explore the world, just as other children, through play. By letting the children use their whole body, the learning activity becomes a multisensory unity of action, perception, cognition, and emotions. Hengeveld et al. [7] list more advantages to tangible interaction for children with multiple disabilities, such as more room for social interaction, a more personal interaction style, a slower

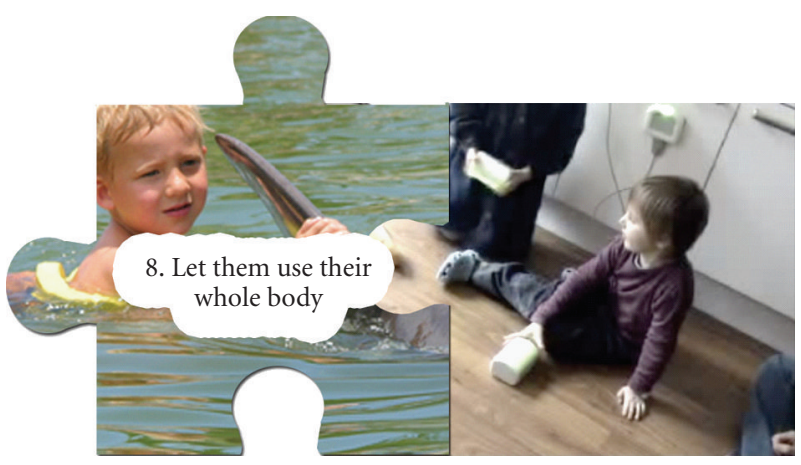

FIgURE 12: Whole body: (a) Beer swims with a dolphin in Florida. (b) Jakob plays with LINKX on the kitchen floor together with his sister.

pace, and a more active interaction. This multisensory unity is visualised in Figure 12 with a picture of Beer during his dolphin therapy in Florida. During the activity itself, he learned how to interact with the dolphin and got rewarded by the sensory experience of the warm water, involving action, perception, cognition, and emotions.

LINKX provided a break from conventional computerassisted language learning, which is mainly screen-based with words linked to drawn pictures of generic objects. LINKX shows how interactive toys can bring word learning to the real familiar environment of the child, involving the whole body, multiple senses, and motor actions. When Jakob played with LINKX, his sister naturally joined his play, because there were more blocks available. On the kitchen floor, she showed him there were more speech-o-grams around him, providing other important learning aspects, such as imitation and turntaking.

\section{Conclusions}

These guidelines were developed on the basis of literature, our own and other people's experience and the development of the LINKX prototype in particular. Especially the real world helped us to shape the prototype and the guidelines. For example, the prototype tests showed us the importance of giving the opportunity to adjust the toy to a child's specific preferences or needs. The aim of this paper is to share these guidelines with the design research community, so that others can use them as stepping-stones in their work leading to more tangible toys for children with autism. We encourage others to use and improve our guidelines, and formulate new ones.

The interest of parents, pedagogues, and psychologists in LINKX shows the value of these guidelines, both to drive design and to open up discussion. This specific example shows how computers can help children to learn in other ways than in front of a computer screen, as is done in the CD-ROM language training games that work so well for children with typical development. By embedding computer intelligence into physical toys, several aspects can help the children enjoy their play in a predictable way. First, cause and effect are immediate at the place of action. Second, the toy 
refers to real objects in their physical familiar environment instead of (symbolic) representations in a generic drawing of an environment. Third, play takes place in a safe environment, their homes, involving their bodily actions and social interactions. These aspects help the children to learn in a way that makes sense to them and should be exploited more in interaction design for these children.

We hope this paper provides some insight into the experiential world of autistic children. In the long term, further research can give more certainty about the causes of autism, and how learning and play can be facilitated for these children. We learned that personal contact with the children was important for understanding and empathy. We hope the guidelines can provide a bridge between the theories and design research community. Moreover, we hope to inspire more designers with this story of Beer, Robbert, and Jakob, who often surprised us with their smart and inventive ways of dealing with the world.

\section{Acknowledgment}

The authors wish to thank the pedagogues, parents, and especially Beer, Robbert, and Jakob, who willingly and enthusiastically took part in the LINKX project.

\section{References}

[1] T. Grandin, Thinking in Pictures, Vintage, New York, NY, USA, 1996.

[2] O. Sacks, An Anthropologist on Mars, Vintage, New York, NY, USA, 1995.

[3] H. van Rijn, LINKX a language toy for autistic toddles, developed in co-creation with parents and pedagogues, M.S. thesis, Delft University of Technology, Delft, The Netherlands, 2007.

[4] H. van Rijn, “The LINKX project,” 2007, http://studiolab.io .tudelft.nl/vanrijn/LINKX.

[5] H. van Rijn and P. J. Stappers, "“Codesigning LINKX": a case of gaining insight in a "difficult-to-reach user group"," in Proceedings of International Association of Societies of Design Research (IASDR '07), The Hong Kong Polytechnic University, Kowloon, Hong Kong, November 2007.

[6] The National Autistic Society, 2000, http://www.nas.org.uk/.

[7] B. Hengeveld, R. Voort, H. van Balkom, C. Hummels, and J. de Moor, "Designing for diversity: developing complex adaptive tangible products," in Proceedings of the 1st International Conference on Tangible and Embedded Interaction (TEI '07), pp. 155-158, Baton Rouge, La, USA, February 2007.

[8] C. de Bruin, Geef me de vijf. Een praktisch houvast bij de opvoeding en begeleiding van kinderen met autisme, Graviant, Doetinchem, The Netherlands, 2004.

[9] American Psychiatric Association, Diagnostic and Statistical Manual of Mental Disorders, American Psychiatric Publishing, Arlington, Va, USA, 4th edition, 2000.

[10] N. Parés, A. Carreras, J. Durany, et al., "Promotion of creative activity in children with severe autism through visuals in an interactive multisensory environment," in Proceedings of the 4th International Conference on Interaction Design and Children (IDC '05), pp. 110-116, Boulder, Colo, USA, June 2005.
[11] S. Baron-Cohen, Mindblindness, MIT Press, Cambridge, Mass, USA, 1995.

[12] L. M. Oberman and V. S. Ramachandran, "The simulating social mind: the role of the mirror neuron system and simulation in the social and communicative deficits of autism spectrum disorders," Psychological Bulletin, vol. 133, no. 2, pp. 310-327, 2007.

[13] K. M. Colby, "The rationale for computer-based treatment of language difficulties in nonspeaking autistic children," Journal of Autism and Developmental Disorders, vol. 3, no. 3, pp. 254260, 1973.

[14] T. R. Goldsmith and L. A. LeBlanc, "Use of technology in interventions for children with autism," Journal of Early and Intensive Behavior Intervention, vol. 1, no. 2, pp. 166-178, 2004.

[15] K. Dautenhahn, "Design issues on interactive environments for children with autism," in Proceedings of the 3rd International Conference on Disability, Virtual Reality and Associated Technologies (ICDVRAT '00), pp. 153-161, Sardinia, Italy, September 2000.

[16] D. J. Cohen and F. R. Volkmar, Handbook of Autism and Pervasive Developmental Disorders, John Wiley \& Sons, New York, NY, USA, 1997.

[17] L. C. Bryan and D. L. Gast, "Teaching on-task and on-schedule behaviors to high-functioning children with autism via picture activity schedules," Journal of Autism and Developmental Disorders, vol. 30, no. 6, pp. 553-567, 2000.

[18] K. L. Pierce and L. Schreibman, "Teaching daily living skills to children with autism in unsupervised settings through pictorial self-management," Journal of Applied Behavior Analysis, vol. 27, no. 3, pp. 471-481, 1994. 

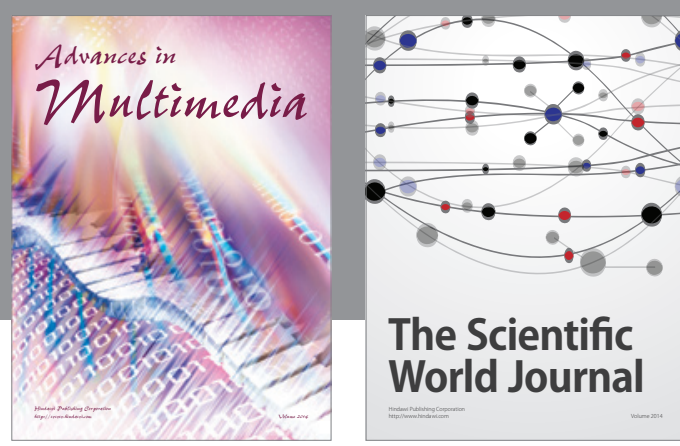

The Scientific World Journal
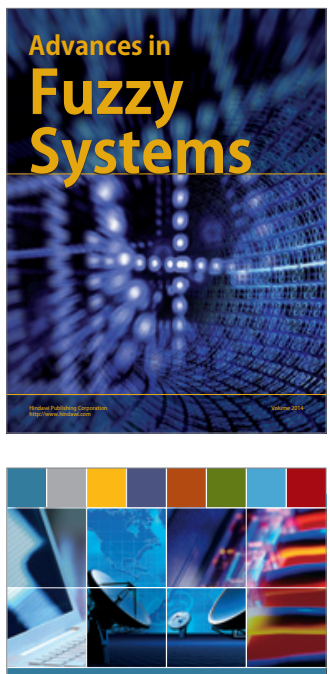

Computer Networks and Communications
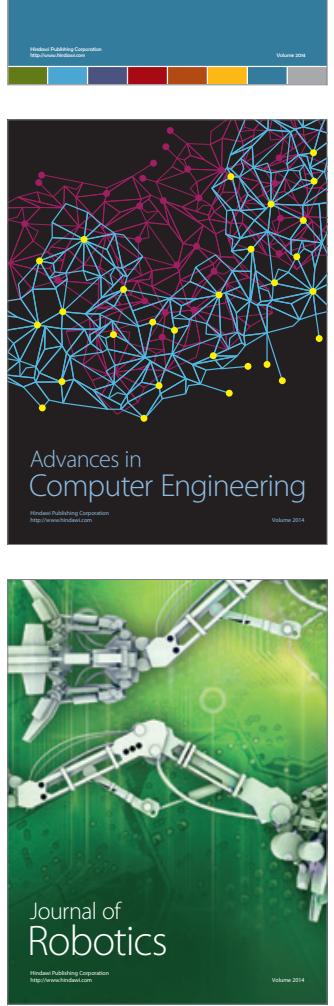
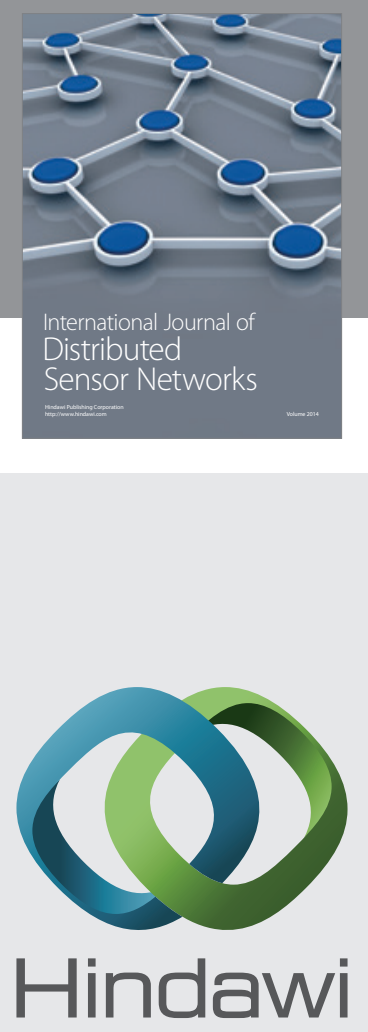

Submit your manuscripts at

http://www.hindawi.com
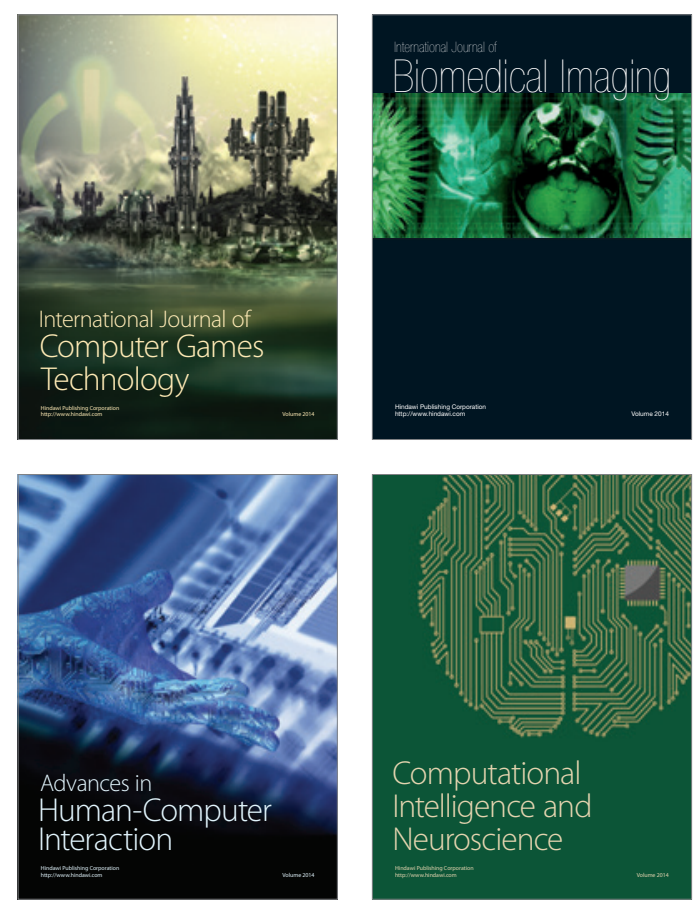
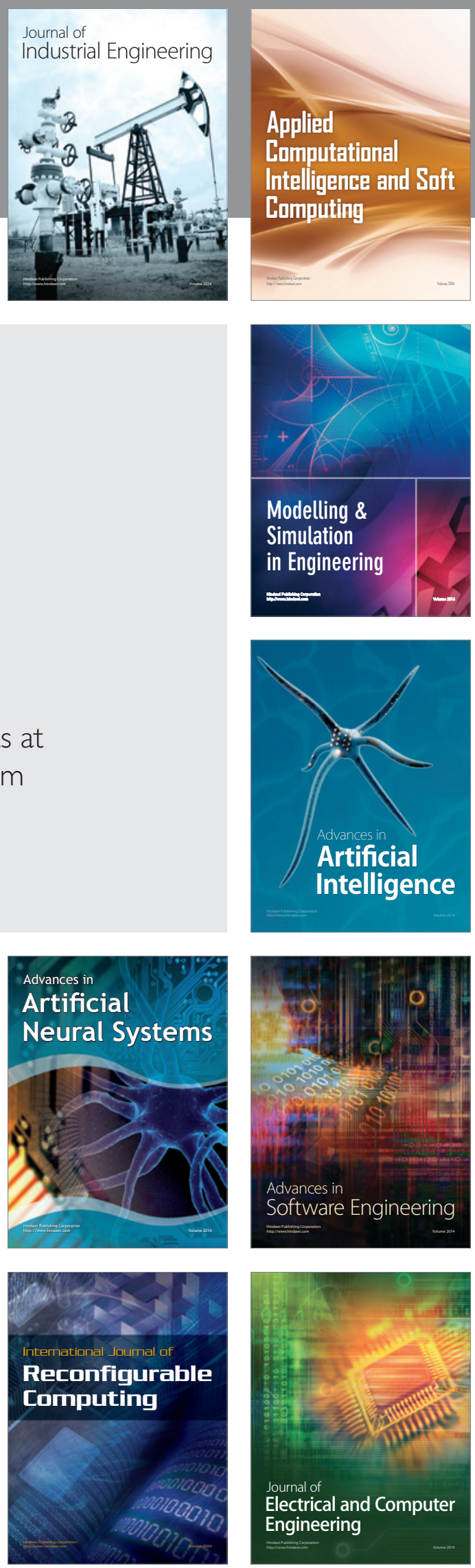